\title{
Binding of isolated rheumatoid factors to histone proteins and basic polycations
}

\author{
R. N. HOBBS,$^{1}$ D. J. LEA,$^{1} \mathrm{~K} . \mathrm{K} . \mathrm{PHUA}^{2}{ }^{2}$ AND P. M. JOHNSON ${ }^{2}$ \\ From the ${ }^{1}$ Department of Rheumatology, Robert Jones and Agnes Hunt Orthopaedic Hospital, Oswestry, Salop \\ SY10 7AG, and ${ }^{2}$ the Department of Immunology, University of Liverpool, PO Box 147, Liverpool L69 $3 B X$
}

SUMMARY A fluorimetric immunoassay has been used to assess reactivity of rheumatoid factor (RF) with both histone proteins and other basic polycations (poly-L-lysine, poly-L-ornithine, and protamine) bound to an immobilised tyrosine-glutamic acid polyanionic copolymer. Isolated RF preparations can bind to histone proteins in this assay, notably to $\mathrm{H} 3$ and $\mathrm{H} 4$ histones, and this activity was always masked in the original whole seropositive sera. Binding of isolated RF was often noted also to the other large-molecular-weight basic polycations.

Several groups have reported that isolated rheumatoid factors (RF) may express reactivity for a cell nuclear determinant as well as for a determinant in the Fc region of IgG. ${ }^{1-4}$ The reaction of RF with cell nuclei can often be masked in studies with whole seropositive sera because of the presence of a vast excess of serum IgG, and hence isolation of an RF fraction is usually important for its detection. ${ }^{23}$ However, this cross-reactive RF specificity is now considered to be of little immunopathological significance, ${ }^{5}$ though it may be of interest in clarifying concepts related to the characteristics of the variable region of RF antibody molecules and approaches towards understanding the genesis of RF production in patients with rheumatoid arthritis (RA). ${ }^{4}$

The cell nuclear determinants reactive with isolated RF are expressed in nuclei of normal cells from most species and are represented within isolated mononucleosome preparations. ${ }^{6}$ It has been concluded that these determinants are conformationally dependent, since they are destroyed when DNA and the core histone proteins are separated from their organised structure with nucleosomes. ${ }^{236}$ Thus, isolated histones in free solution are unreactive with $\mathrm{RF}$ preparations. ${ }^{236}$ The present study has utilised a sensitive fluorimetric assay for antihistone antibodies to assess RF reactivity with both histone proteins and other basic polycations bound to an immobilised tyrosine-glutamic acid (tyr-glu) copolymer. The spatial orientation of histone proteins bound to this

Accepted for publication 21 May 1982.

Correspondence to Dr R. N. Hobbs, Department of Rheumatology, Robert Jones and Agnes Hunt Orthopaedic Hospital, Oswestry, Salop SY10 7AG. acidic copolymer may resemble that of these proteins bound to their natural polyanionic ligand, that is, DNA. It has been shown that isolated RF can bind to histone proteins, notably $\mathrm{H} 3$ and $\mathrm{H} 4$, held in this stereospecific form, and that RF may also bind to other polycations.

\section{Materials and methods}

$R F$ preparations. RF preparations were isolated from seropositive RA sera of high titre by affinity chromatography using immobilised heat-aggregated IgG as described previously. ${ }^{25}$ One of the original whole sera (no. 2) gave weak homogeneous antinuclear antibody (ANA) staining on tissue section immunofluorescence (titre: 128), whereas the remainder of the whole sera showed no ANA activity. Isolated RF preparations were dialysed against phosphate-buffered isotonic saline, $\mathrm{pH} 7 \cdot 2$, concentrated to $1 \mathrm{mg} / \mathrm{ml}(1 \mathrm{~g} / \mathrm{l})$ protein and stored frozen in small aliquots with addition of $10 \%$ glycerol. All preparations showed RF reactivity with IgG in agglutination assays and also cross-reactivity with cell nuclei in tissue section immunofluorescence. ${ }^{2}$ For use as a control an IgM $\kappa$ preparation was isolated from the serum of a patient with Waldström's macroglobulinaemia as described elsewhere. ${ }^{7}$ No RF or ANA activity was detected in this patient's serum or isolated IgM $\kappa$ paraprotein.

Antihistone antibody assay. Antihistone antibody activity was assessed by a fluorimetric immunoassay to be described in detail elsewhere (Hobbs and Lea, in preparation). Briefly, the tyr-glu copolymer (1:1 composition, molecular weight 66000 , from Miles 
Laboratories, Slough, UK) was absorbed by hydrophobic interaction on to polystyrene EIA cuvettes (Gilford Instruments, London, UK). This was performed by addition to each cuvette of $100 \mu$ l polymer solution in $0.05 \mathrm{M}$ borate buffer containing $50 \mathrm{mM}$ $\mathrm{NaCl}, \mathrm{pH} \mathrm{8.2.} \mathrm{After} \mathrm{sealing} \mathrm{with} \mathrm{Parafilm} \mathrm{M}$, the cuvettes were incubated at $20^{\circ} \mathrm{C}$ overnight and unbound polymer then removed by thorough washing with distilled water. Mixed histones (type II-AS, from Sigma Chemical Co., Poole, UK) derived by extraction of calf thymus, or individual histones purified from pig (for $\mathrm{H} 1$ and $\mathrm{H} 3$ ) or calf (for $\mathrm{H} 2 \mathrm{~A}$, H2B, H4) thymuses (a gift from Dr E. W. Johns, Institute of Cancer Research, Royal Cancer Hospital, London), were absorbed on to the polyanionic polymer surface by addition to each cuvette of $100 \mu \mathrm{l}$ of histone solution $(100 \mathrm{mg} / \mathrm{l})$ in the borate- $\mathrm{NaCl}$ buffer, $\mathrm{pH} 8 \cdot 2$, and incubated overnight as previously described. Unbound histones were then removed by thorough washing with the borate- $\mathrm{NaCl}$ buffer. A $1: 20$ dilution of test serum or $10 \mu \mathrm{g} / \mathrm{ml}(10 \mathrm{mg} / \mathrm{l})$ isolated RF preparation in the borate- $\mathrm{NaCl}$ buffer containing also $0.1 \%$ Tween 20 was added, incubated at $20^{\circ} \mathrm{C}$ overnight, and then washed thoroughly with the borate-NaCl-Tween buffer. Fluorescein isothiocyanate (FITC)-conjugated sheep antihuman immunoglobulin (Wellcome Reagents, Beckenham, $\mathrm{UK})$ at 1:60 dilution in the borate-NaCl-Tween buffer containing also $5 \%$ normal sheep serum was added to each cuvette and incubated at $20^{\circ} \mathrm{C}$ for 6 hours before removal of unbound FITC-conjugate by thorough washing with the borate- $\mathrm{NaCl}-\mathrm{Tween}$ buffer. Bound FITC-conjugate was then removed by addition of $750 \mu \mathrm{l}$ of $0.2 \%$ sodium dodecyl sulphate in $0.1 \mathrm{M} \mathrm{NaOH}$ and fluorescence of the resultant solution measured in a Locarte digital fluorimeter as described in detail by Lea and Ward. ${ }^{9}$ The fluorimeter was calibrated such that a 1:12000 dilution of the FITC-conjugate alone gave a reading of $1 \cdot 00$.
Basic polycations. Poly-L-lysines (PLL) of mean molecular weights (MWs) 350000,13000 , and 3000 , poly-L- $\alpha$-ornithine (mean MW 40000 ) and salmon sperm protamine (grade IV) were obtained from Sigma Chemical Co., Poole, UK. Reactivity with RF or non-RF IgM preparations was assessed by fluorimetric immunoassay essentially as described above but with these polycations absorbed directly on to plain polystyrene EIA cuvettes after overnight incubation at $20^{\circ} \mathrm{C}$ at a concentration of $100 \mathrm{mg} / \mathrm{l}$ in the borate- $\mathrm{NaCl}$ buffer, $\mathrm{pH} 8 \cdot 2$.

\section{Results}

The binding activity to histone proteins in the fluorimetric assay for paired samples of whole seropositive RA sera and corresponding RF preparations is given in Table 1. These values for sera and RF preparations are compared with those of a whole normal human serum (lacking RF and ANA activity) and an isolated non-RF IgM $\kappa$ protein. Binding to the polyanionic tyr-glu copolymer alone in all cases was very low. Only one of the RA sera (no. 2) showed significant antihistone antibody activity. This reactivity was not strong and was manifest against all individual histones and a mixed histone preparation, although reactivity with $\mathrm{H} 1$ and $\mathrm{H} 2 \mathrm{~A}$ was slightly more pronounced (Table 1). In contrast, 2 of the 3 isolated RF preparations (nos. 1 and 3) showed significant reactivity compared with non-RF IgM, and this reactivity was most pronounced against $\mathrm{H} 3$ and $\mathrm{H} 4$ histone proteins (Table 1). When RF preparation no. 3 was added to a normal human serum (final concentration $20 \mu \mathrm{g} / \mathrm{ml}(20 \mathrm{mg} / \mathrm{l})$ in a $1: 20$ dilution of serum), the fluorescence value for reactivity against each of the histone preparations was reduced in every case to less than $20 \%$. With the use of FITC-labelled mixed histones the amount of histone bound to the immobilised polyanionic tyr-glu copolymer was determined to be 3.0 times greater

Table 1 Histone-binding activity in 3 paired seropositive $R A$ sera and isolated $R F$ preparations

\begin{tabular}{|c|c|c|c|c|c|c|c|c|}
\hline \multirow{3}{*}{$\begin{array}{l}\text { Histone } \\
\text { preparation }\end{array}$} & \multicolumn{8}{|c|}{ Fluorescence value } \\
\hline & \multicolumn{4}{|c|}{ Whole sera } & \multicolumn{4}{|c|}{$\boldsymbol{R} F$ preparations: } \\
\hline & No. 1 & No. 2 & No. 3 & NHS & No. 1 & No. 2 & No. 3 & Non-RF IgM \\
\hline Mixed histones & $0 \cdot 16$ & 0.41 & $0 \cdot 13$ & 0.06 & $1 \cdot 31$ & 0.73 & $1 \cdot 76$ & 0.63 \\
\hline H1 & $0 \cdot 17$ & 0.53 & 0.09 & 0.06 & 0.45 & $0 \cdot 12$ & 0.73 & 0.33 \\
\hline H2B & $0 \cdot 14$ & $0 \cdot 38$ & $0 \cdot 14$ & 0.04 & 0.95 & 0.44 & $1 \cdot 22$ & $0 \cdot 48$ \\
\hline H3 & $0 \cdot 17$ & $0 \cdot 36$ & 0.15 & 0.07 & $1 \cdot 42$ & 0.82 & $1 \cdot 87$ & 0.58 \\
\hline H4 & $0 \cdot 14$ & 0.34 & $0 \cdot 15$ & $0 \cdot 12$ & $1 \cdot 40$ & 0.78 & $1 \cdot 80$ & 0.55 \\
\hline No added histone & 0.03 & 0.05 & 0.05 & 0.01 & 0.03 & $0 \cdot 04$ & 0.06 & 0.02 \\
\hline
\end{tabular}

NHS $=$ whole normal human serum. 
Table 2 Basic polycation-binding activity of isolated $R F$ preparations

\begin{tabular}{|c|c|c|c|c|c|c|}
\hline \multirow{3}{*}{$\begin{array}{l}\text { Basic } \\
\text { polycation }\end{array}$} & \multirow{3}{*}{$\begin{array}{l}\text { Mean } \\
M W\end{array}$} & \multicolumn{5}{|c|}{ Fluorescence value } \\
\hline & & \multicolumn{5}{|c|}{$R F$ preparations } \\
\hline & & No. 1 & $\begin{array}{c}\text { No. } 2 \\
-\end{array}$ & No. 3 & No. 4 & $\begin{array}{l}\text { Non-RF } \\
\text { IgM }\end{array}$ \\
\hline PLL & 350000 & $1 \cdot 65$ & 0.43 & $2 \cdot 20$ & $0 \cdot 86$ & $0 \cdot 39$ \\
\hline PLL & 13000 & 0.97 & $0 \cdot 34$ & 0.58 & $0 \cdot 17$ & $0 \cdot 21$ \\
\hline PLL & 3000 & $0 \cdot 88$ & $0 \cdot 15$ & NT & NT & 0.01 \\
\hline Polyornithine & 40000 & 0.99 & $0 \cdot 16$ & 1.90 & $0 \cdot 87$ & $0 \cdot 31$ \\
\hline Protamine & 5000 & 3.35 & 0.21 & $0 \cdot 13$ & 0.06 & 0.06 \\
\hline
\end{tabular}

PLL = poly-L-lysines. NT= not tested.

than that bound to the plain polystyrene cuvettes, whereas RF reactivity with mixed histones was increased 6-10 fold.

The binding activity of isolated RF preparations for different basic polycations in the fluorimetric assay is given in Table 2 . Three of $4 \mathrm{RF}$ preparations bound significantly to high molecular weight PLL, and this activity decreased markedly for PLL polymers of lower molecular weights (Table 2). Furthermore, $3 \mathrm{RF}$ preparations showed significant binding to polyornithine, and one preparation also bound strongly to protamine (Table 2).

\section{Discussion}

It has been established that both DNA and histones might be involved in the expression of the cell nuclear determinants reactive with isolated $R^{2}{ }^{36}$ and presumed that these determinants may be expressed on histones only when orientated in a particular conformation on DNA. ${ }^{34}$ The reactivity of isolated RF preparations with individual and mixed histones extracted from nuclei has been investigated in a fluorimetric immunoassay with a solid-phase coated with an polyanionic tyr-glu copolymer. It has been shown ${ }^{10}$ that polyanions produced from glutamic and acid or aspartic acid mimic assembly proteins ${ }^{11}$ and can organise core histone proteins into octamers similar to those found in nucleosomes. The structure of histone mixtures bound to the polyanionic tyr-glu copolymer may resemble that of these proteins bound to DNA.

RF preparations can bind to histone proteins in this assay, notably to $\mathrm{H} 3$ and $\mathrm{H} 4$ histones, and this activity was always masked in the original whose seropositive sera used in this study. However, it is of note that whole sera of RA patients with systemic vasculitis often show greatest antihistone antibody activity against both $\mathrm{H} 2 \mathrm{~A}$ and $\mathrm{H} 3$ histones, unlike, for example, the sera of systemic lupus erythematosus patients (Hobbs and Lea, in preparation). In contrast to the present report a previous study ${ }^{3}$ has suggested that RF cross-reactivity with histone proteins may be particularly directed to the $\mathrm{H} 2 \mathrm{~A}$ and $\mathrm{H} 2 \mathrm{~B}$ histones. This was assessed by experiments in which solutions containing purified histone fractions were added to cell nuclei that had been stripped by mild acid treatment. The constitution of structures produced by this technique has not been described, although it is known that reconstitution of nucleosomes with soluble DNA usually requires the presence of an assembly protein, ${ }^{11}$ whereas DNA precipitates histones in solution.

Isolated RF preparations have been shown to bind to other high-molecular-weight polycations such as poly-L-lysine, poly-L-ornithine, and protamines immobilised directly on plain polystyrene. Thus the binding of RF to nucleosomes may be at locations primarily determined by the availability of free basic groups. Indeed the reactivity of isolated RF preparations with polycations, including histone proteins, may at present best not be described as immunological cross-reactions with different antigenic groupings, which implies multiple specificities contributing to the antigen-binding site in the hypervariable regions of RF immunoglobulin molecules. Rather it would appear that there may be at least one unusual structure within the variable region of some RF molecules, but not necessarily integral within the finite antigen combining site of the RF molecules, that promotes apparent reactivity of this protein with a variety of basic polycations. However, other factors than ionic interactions may contribute to such RF binding, since the binding of isolated RF with cell nuclei is optimal at more alkaline $\mathrm{pH},{ }^{5}$ when there would be less ionisation of basic groupings, and also it has been reported that isolated $\mathrm{RF}$ may bind to nonbasic groupings such as the di- and trinitrophenyl haptenic groups. ${ }^{12}$

We thank Dr E. W. Johns and R. H. Nicolas for the gift of purified histone preparations. This work was supported by a grant from the Arthritis and Rheumatism Council.

\section{References}

1 Hannestad K. Certain rheumatoid factors react with both IgG and an antigen associated with cell nuclei. Scand $J$ Immunol 1978; 7: 127-36.

2 Johnson P M. IgM-rheumatoid factors cross-reactive with IgG and a cell nuclear antigen: apparent 'masking' in original serum. Scand J Immunol 1979; 9: 461-6.

3 Agnello V, Arbetter A, Ibanez de Kasep G, Powell R, Tan E M, Joslin F. Evidence for a subset of rheumatoid factors that crossreact with DNA-histone and have a distinct cross-idiotype. $J$ Exp Med 1980; 151: 1514-27.

4 Johnson $P$ M. Molecular nature and cross-reactions of rheumatoid factor. Clin Immunol Allergy 1981; 1: 103-115. 
5 Johnson P M. IgM-rheumatoid factors cross-reactive with IgG and a cell nuclear antigen: immunopathological implications? Ann Rheum Dis 1980; 39: 586-8.

6 Hannestad K, Stollar B D. Certain rheumatoid factors react with nucleosomes. Nature 1978; 275: 671-3.

7 Morgan M R A, Johnson P M, Dean P D G. Electrophoretic desorption of immunoglobulins from immobilised protein $A$ and other ligands. J Immunol Methods 1978; 23: 381-7.

8 Johns E W. The isolation and purification of histones. In: Stein G, Stein J, Kleinsmith J, eds. Methods in Cell Biology. New York: Academic Press, 1977: 16: 183-203.
9 Lea D J, Ward D J. Estimation of IgM rheumatoid factor by fluorimetry. Ann Rheum Dis 1978; 37: 247-51.

10 Stein A, Whitlock J P, Bina M. Acidic polypeptides can assemble both histones and chromatin in vitro at physiological ionic strength. Proc Natl Acad Sci USA 1979; 76: 5000-4.

11 Laskey R A, Honda B M, Mills A D, Finch J T. Nucleosomes are assembled by an acidic protein which binds histones and transfers them to DNA. Nature 1978; 275: 416-20.

12 Hannestad K. Monoclonal and polyclonal $\gamma \mathrm{M}$-rheumatoid factors with anti-di and anti-trinitrophenyl activity. Clin Exp Immunol 1967; 4: 555-78. 